\title{
External auditory canal cholesteatoma: A case report
}

\author{
Indira Acharya* and Pabina Rayamajhi \\ GMSMA of ENT-HN Studies, MMC-TUTH, IOM, Nepal
}

Received: 制June 12, 2018; Published: 制 June 19, 2018

*Corresponding author: Indira Acharya, GMSMA of ENT-HN Studies, MMC-TUTH, IOM, Nepal.

\section{Abstract}

We present a case of cholesteatoma of external auditory canal with invasion to atic, aditus and antrum. Tympanic membrane remained intact. Malleus, incus and stapes supra structure were absent with dehiscent horizontal segment of facial nerve. Cochlea was totally dehiscent. Symptoms were only chronic otorrhoea and hearing impairment. Diagnosis was based on clinical analysis. CT Scan was used to measure pathology. Treatment was Modified radical mastoidectomy associated with meatoplasty.

Introduction

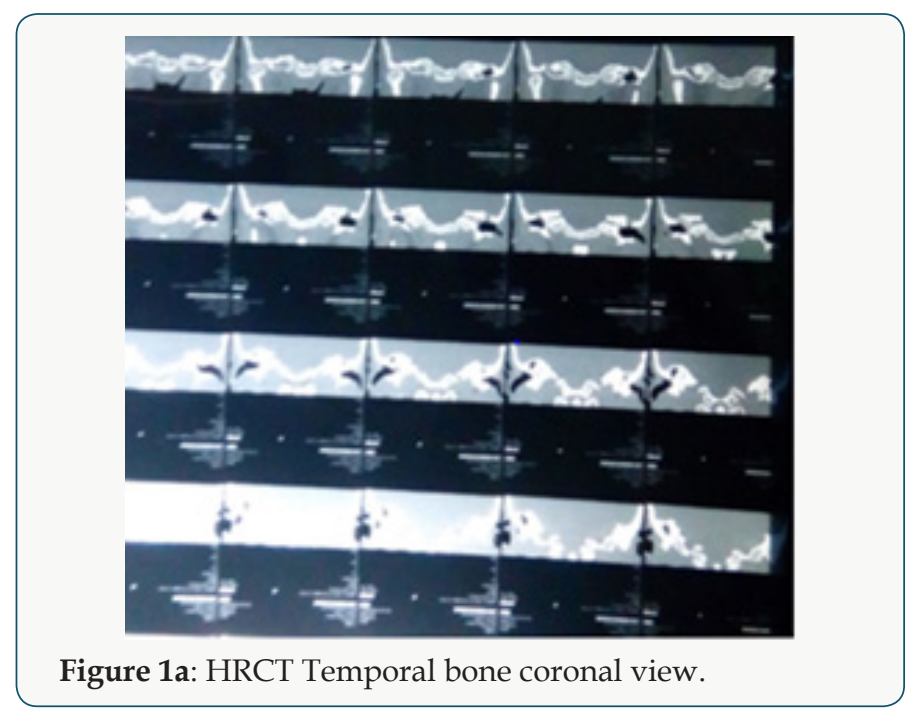

17 years old female, presented to Otorhinolaryngological outpatient department of IOM, TUTH with complains of bilateral ear discharge and bilateral decreased hearing since childhood. She had a history of right atticotomy with PORP placement 2 years back. Since then there is no history of discharge from right ear. Otoscopy showed intact left tympanic membrane with cholesteatoma in left external auditory canal attached with posterosuperior part of pars tense and posterior atic. Pure tone audiometry showed $40 \mathrm{~dB}$ mild conductive hearing loss in right ear and $59 \mathrm{~dB}$ moderate conductive hearing loss in left ear. Cholesteatoma of external canal was suspected and high resolution CT scan of temporal bone was requested. CT scan showed soft tissue density in left external auditory canal and left mastoid cavity (Figures 1a \& 1b). Intraoperative observation revealed cholesteatoma in left external auditory canal, atic, aditus and antrum. Dural plate and semicircular canal were intact. However sinus plate was exposed, facial nerve was dehiscent in horizontal segment. Cochlea was totally dehiscent (Figure2). Regarding ossicular status malleus, incus and stapes supra structure were totally absent. We conducted Left modified radical mastoidectomy with meatoplasty.

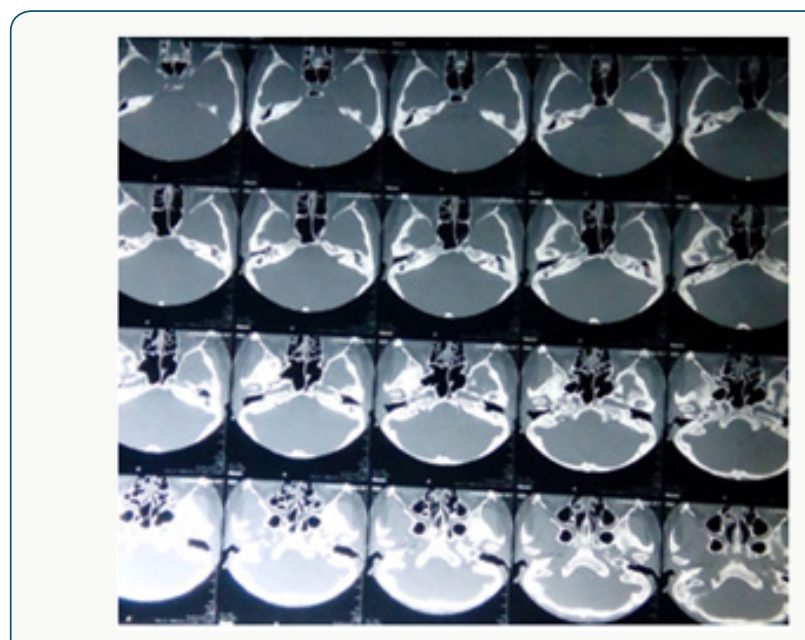

Figure 1b: HRCT Temporal bone axial view. 


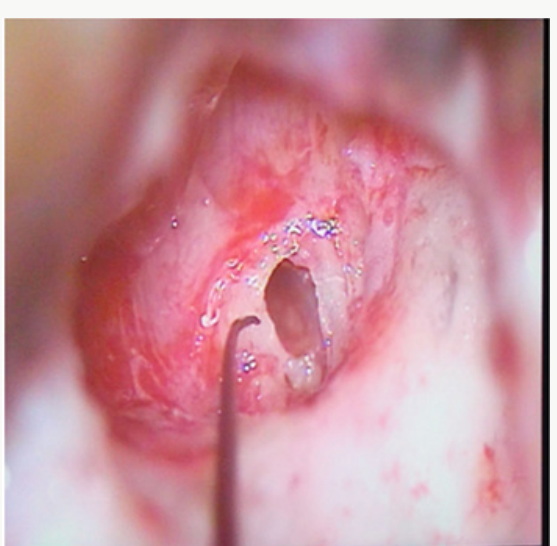

Figure 2: Dehiscent cochlea.

\section{Discussion}

Cholesteatoma rarely originates from external auditory canal. External auditory cholesteatoma has a incidence of about $0.1-0.5 \%$ in new patients with ear problems [1-3]. Progression of disease is slow, thus it is evident especially in elderly people $[4,5]$. It can affect adjacent structures (lateral sinus, facial nerve, posterior cranial fossa). Therefore, a CT scan is recommended for all patients $[1,2,6,7]$. Surgery is the treatment of choice, whose main purpose is to eradicate the lesion and, if possible, preserve the patient's hearing acuity [8].

\section{References}

1. Malcom PN, Francis IS, Wareing MJ, Cox TCS (1997) CT Appearances of External Ear Canal Cholesteatoma. The British Journal of Radiology 70(837): 959-960.

2. Garin P, Degols JC, Delos M (1997) External Auditory Canal Cholesteatoma. Otolaryngol Head Neck Surg 123(1): 62-65.

3. Birzgalis AR, Farrington WT, Hartley C, Hartley RH, Lyons TJ (1995) External Ear Canal Cholesteatoma. Ann Otol Rhinol Laryngologia 104(11): 868-870.

4. Zenine D Fabio, Ameno S Everton (2005) Cholesteatoma of External auditory canal: A case report. Revista Brasileira de otorhinolaryngoloiavol 71(1): 91-93.

5. Lee Dong Hee (2005) A case of osteoma with cholesteatoma in the external auditory canal. Aurus Nasus Larynx 32(3): 281-284.

6. Coelho LB, Delegido RM, Finamore CMJM, Rodrigues J, Secchi MMD (2000) Cholesteatoma of External Auditory Canal. Rev Bras de Otorrinolaringol 66(3): 285-288.

7. Omezzine Jerbi S, Dakkem M (2013) Spontaneous cholesteatoma of External auditory canal: the utility of CT. Journal de Radiologie Diagnostique et Interventionnelle 94(4): 438-442.

8. Heiburn E Marta, Salzman L Karen (2001) External Canal Cholesteatoma. Clinical and imaging spectrum. American journal of neurotology

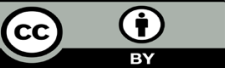

This work is licensed under Creative Commons Attribution 4.0 License

To Submit Your Article Click Here:

Submit Artic

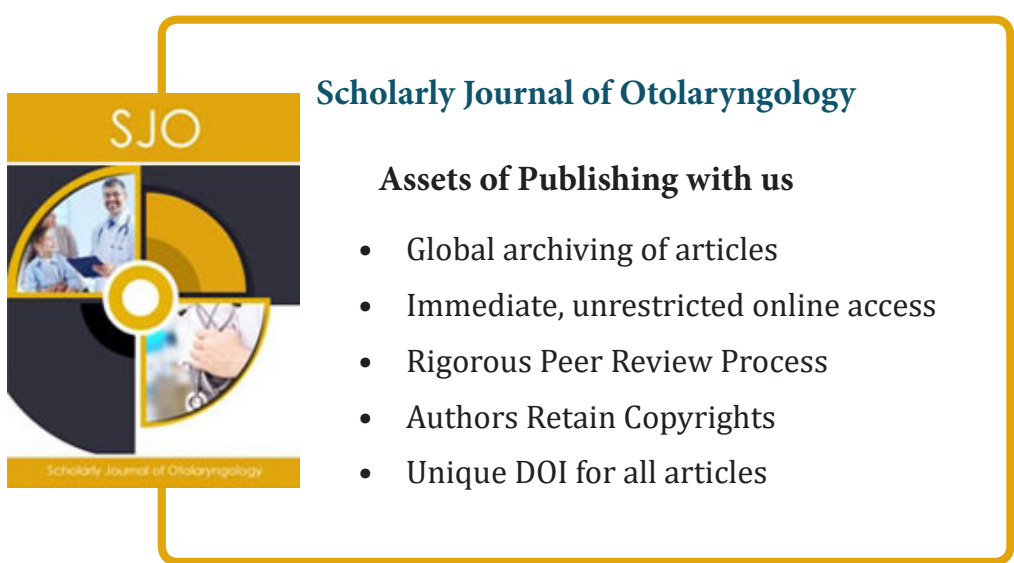

